\title{
CHEMOTHERAPY IN RECTAL CANCER
}

\author{
Bohdan Tataryn, Anna Kryzhanivska, Volodymyr Holotiuk, Alina Andriiv, Olha Ivantsiv \\ IVANO-FRANKIVSK NATIONAL MEDICAL UNIVERSITY, IVANO-FRANKIVSK, UKRAINE
}

\begin{abstract}
The aim: To evaluate and analyze early and late results of treatment of patients with rectal cancer after chemotherapy.

Materials and methods: The study is based on the results of observation of 779 patients with stage II, III and IV rectal cancer (RC) who were divided into groups according to the chemotherapy treatment.

Results: In the course of chemotherapy treatment of RC patients, most of them received the FOLFOX regimen treatment - 87 patients (43.5\%). 40 people (20\%) received Mayo regimen. 36 patients (18\%) underwent FOLFIRI regimen. Another 33 patients received the XELOX regimen chemotherapy (16.5\%). In four cases, patients underwent Tegafur monotherapy (2\%).

Conclusions: The obtained data for patients with stage III RC showed that at all studied time intervals, the highest percentage of surviving patients was recorded in those who received chemotherapeutic treatment according to the FOLFOX regimen. In patients with stage II RC, the most effective was Mejo regimen - 30.7\% (survived patients for the 5 year observation).
\end{abstract}

KEY WORDS: complex treatment of rectal cancer, rectal cancer, chemotherapy treatment of cancer

\section{INTRODUCTION}

Every year, about 100 thousand new cases of rectal cancer (RC) are diagnosed in Europe, in the USA - more than 40 thousand $[1,2]$.

According to the National Cancer Registry of Ukraine, in the structure of the incidence of malignant neoplasms $(\mathrm{MN})$ of the population of Ukraine (excluding non-melanoma skin MN), RC accounts for 5.4\% among women, and $6.8 \%$ among men. $6.1 \%$ of women and $7.2 \%$ of men aged $55-74$ suffer from RC. $7.3 \%$ of women over 75 years have this disease.

In the structure of mortality of the Ukraine's population from $\mathrm{MN}, \mathrm{RC}$ was diagnosed in $6.2 \%$ of men aged $55-74$ years, and in $9.1 \%$ of those who are 75 and older. Among women of 75 years and older - in 8.4\% (2018 - updated information).

According to the National Cancer Registry of Ukraine, in $2019,23.7 \%$ and $19.7 \%$ of the initially identified patients with RC had stage III and IV, respectively. $72.1 \%$ of patients underwent special treatment in 2019. Mortality up to one year was $25.4 \%$ [3].

Combination therapy is the main method of treatment of rectal cancer patients. It includes surgical treatment, radiation and polychemotherapy (PCT) in different sequences $[4,5]$.

Rectal cancer has long been considered a radioresistant tumour. However, significant progress has been made in recent years in the treatment of RC patients through the use of neoadjuvant chemotherapy (NACT). This approach allows to obtain satisfactory results and regression of the primary tumour in patients with stages I-II of the disease $[6,7]$.

For about $30 \%$ of patients with locally advanced RC, the performance of sphincter-preserving surgical intervention is impossible [8]. There is no definitive treatment and diagnostic standard for locally advanced RC (LARC), unlike for localized forms. For a long time, total mesorectumectomy and fluoropyrimidine-based NACT have been used in the treatment of patients with LARC [9]. Radiation therapy (RT) overregulates with one of the enzymes of activation of fluoropyrimidines thymidine phosphorylase within the tumour, which explains the effectiveness of FU/CAP $[10,11$, 12]. Oxaliplatin is also a promising drug in the treatment of patients; in a number of studies, it has demonstrated potential as a radiosensitizing agent $[13,14,15]$. The safety and efficacy of the combination of CAP and XELOX in patients with LARC currently need further study.

According to "the NCCN Clinical Practice Guidelines in Oncology: Colon Cancer", chemotherapy is indicated for patients with stage II RC in the case of adverse factors, namely the FOLFOX-6 regimen. Capecitabine and 5-FU for these patients are similar in efficacy, with no proven benefit of oxaliplatin addition.

FOLFOX-6 and CapeOX show greater efficacy at stage III RC compared to the Mejo regimen.

According to the NCCN recommendations, the duration of chemotherapy treatment is 6 months. CT in patients over 75 years of age with stage III RC should be based on the presence of concomitant pathology. 
Table I. Overall survival rates of patients with rectal cancer (\%) II stage

\begin{tabular}{ccccccccc}
\hline $\begin{array}{c}\text { Time of } \\
\text { observation, } \\
\text { month }\end{array}$ & FOLFIRI & FOLFOX & XELOX & Mejo & FOLFIRI & FOLFOX & XELOX & Mejo \\
\cline { 2 - 9 } & 96,9 & 98,4 & 89,3 & 97,9 & $\pm 4,3$ & $\pm 2,3$ & $\pm 10,2$ & $\pm 2,9$ \\
\hline 6 & 90,6 & 96,3 & 65,1 & 95,9 & $\pm 7,3$ & $\pm 3,6$ & $\pm 18,7$ & $\pm 4,0$ \\
\hline 12 & 68,4 & 68,5 & & 74,4 & $\pm 12,4$ & $\pm 9,9$ & $\pm 9,0$ \\
\hline 24 & 54,3 & 52,7 & & 53,5 & $\pm 14,3$ & $\pm 11,1$ & $\pm 10,6$ \\
\hline 36 & 21,7 & 43,1 & & 37,6 & $\pm 13,2$ & $\pm 11,5$ & $\pm 10,8$ \\
\hline 48 & 5,4 & 23,5 & & 30,7 & $\pm 7,4$ & $\pm 12,4$ & $\pm 10,8$ \\
\hline 60 & & & & & & & & \\
\hline
\end{tabular}

Table II. Overall survival rates of patients with rectal cancer (\%) III stage

\begin{tabular}{cccccccccc}
\hline $\begin{array}{c}\text { Time of } \\
\text { observation, } \\
\text { month }\end{array}$ & FOLFIRI & FOLFOX & XELOX & Mejo & FOLFIRI & FOLFOX & XELOX & Mejo \\
\hline 6 & 96,0 & 98,3 & 95,7 & 94,4 & $\pm 5,5$ & $\pm 2,4$ & \pm 6 & $\pm 7,6$ \\
\hline 12 & 78,5 & 89,4 & 90 & 61,1 & \pm 12 & $\pm 6,4$ & $\pm 9,6$ & $\pm 16,2$ \\
\hline 24 & 42,1 & 54,2 & 37,5 & 39,6 & \pm 17 & $\pm 12,1$ & $\pm 20,4$ & $\pm 17,8$ \\
\hline 36 & & 32,5 & & 27,5 & & $\pm 16,8$ & $\pm 15,9$ \\
\hline 48 & & & 16,5 & & & & & \\
\hline
\end{tabular}

Table III. Overall survival rates of patients with rectal cancer (\%)

\begin{tabular}{|c|c|c|c|c|c|c|c|c|}
\hline \multirow{2}{*}{$\begin{array}{l}\text { Time of } \\
\text { observation, } \\
\text { month }\end{array}$} & \multicolumn{4}{|c|}{$\%$ of patients survived } & \multicolumn{4}{|c|}{ Standard error } \\
\hline & FOLFIRI & FOLFOX & XELOX & Mejo & FOLFIRI & FOLFOX & XELOX & Mejo \\
\hline 6 & 97,2 & 99,3 & 96,7 & 95,0 & $\pm 2,8$ & $\pm 0,9$ & $\pm 3,2$ & $\pm 3,4$ \\
\hline 12 & 85 & 87,7 & 79,2 & 84,9 & $\pm 6,2$ & $\pm 4,2$ & $\pm 8,4$ & $\pm 5,7$ \\
\hline 24 & 58,1 & 56,7 & 39,3 & 57,4 & $\pm 9,5$ & $\pm 7,1$ & $\pm 12,6$ & $\pm 8,1$ \\
\hline 36 & 33,5 & 42,5 & 9,2 & 43,8 & $\pm 10,1$ & $\pm 7,6$ & $\pm 10,7$ & $\pm 8,4$ \\
\hline 48 & 13,4 & 30,8 & & 33,2 & $\pm 8,4$ & $\pm 8,0$ & & $\pm 8,3$ \\
\hline 60 & 3,4 & 14,2 & & 28,0 & $\pm 4,6$ & $\pm 7,8$ & & $\pm 8,5$ \\
\hline
\end{tabular}

Table IV. Age structure of patients in correlation with the chemotherapy regimen

\begin{tabular}{ccccc}
\hline \multirow{2}{*}{ Regimen of chemotherapy treatment } & \multicolumn{3}{c}{ Average age of patients } \\
\cline { 2 - 5 } & II stage & III stage & IV stage \\
\hline FOLFIRI & $60,6 \pm 8$ & $56,2 \pm 7,8$ & $63,2 \pm 4,5$ \\
\hline FOLFOX & $58,9 \pm 10,1$ & $59,8 \pm 9,9$ & $59,1 \pm 6,6$ \\
\hline XELOX & $56,1 \pm 12$ & $52,3 \pm 12,4$ & $55,1 \pm 6,8$ \\
\hline Majo & $56,6 \pm 10,3$ & $53,2 \pm 16,6$ & - & 72 \\
\hline Tegafur & $63 \pm 8,5$ & & 7,3 \\
\hline
\end{tabular}

Table V. The effectiveness of the FOLFOX regimen at different stages of rectal cancer

\begin{tabular}{cccc}
\hline \multirow{2}{*}{$\begin{array}{c}\text { Time of observation, } \\
\text { month }\end{array}$} & \multicolumn{2}{c}{ \% of patients who survived the FOLFOX treatment regimen } \\
\cline { 2 - 4 } & II stage & III stage & II-IV stage \\
\hline 6 & 98,4 & 98,3 & 99,3 \\
\hline 12 & 96,3 & 89,4 & 57,7 \\
\hline 24 & 68,5 & 32,5 & 56,7 \\
\hline 36 & 52,7 & & 42,5 \\
\hline 48 & 43,1 & & 30,8 \\
\hline 60 & 23,5 & 14,2 & \\
\hline
\end{tabular}


Table VI. The effectiveness of the FOLFIRI regimen at different stages of rectal cancer

\begin{tabular}{|c|c|c|c|}
\hline \multirow{2}{*}{$\begin{array}{c}\text { Time of observation, } \\
\text { month }\end{array}$} & \multicolumn{3}{|c|}{$\%$ of patients who survived the FOLFIRI treatment regimen } \\
\hline & Il stage & III stage & II-IV stage \\
\hline 6 & 96,9 & 96,0 & 97,2 \\
\hline 12 & 90,6 & 78,5 & 85 \\
\hline 24 & 68,4 & 42,1 & 58,1 \\
\hline 36 & 54,3 & & 33,5 \\
\hline 48 & 21,7 & & 13,4 \\
\hline 60 & 5,4 & & 3,4 \\
\hline
\end{tabular}

Table VII. The effectiveness of the XELOX regimen at different stages of rectal cancer

\begin{tabular}{|c|c|c|c|}
\hline \multirow{2}{*}{$\begin{array}{c}\text { Time of observation, } \\
\text { month }\end{array}$} & \multicolumn{3}{|c|}{$\%$ of patients who survived the XELOX treatment regimen } \\
\hline & Il stage & III stage & II-IV stage \\
\hline 6 & 89,3 & 95,7 & 96,7 \\
\hline 12 & 65,1 & 90 & 79,2 \\
\hline 24 & & 37,5 & 39,3 \\
\hline 36 & & & 9,2 \\
\hline \multicolumn{4}{|l|}{48} \\
\hline 60 & & & \\
\hline
\end{tabular}

Table VIII. The effectiveness of the Mejo regimen at different stages of rectal cancer

\begin{tabular}{cccc}
\hline \multirow{2}{*}{$\begin{array}{c}\text { Time of observation, } \\
\text { month }\end{array}$} & \multicolumn{2}{c}{ \% of patients who survived the Mejo treatment regimen } \\
\cline { 2 - 4 } & II stage & III stage & II-IV stage \\
\hline 6 & 97,9 & 94,4 & 95,0 \\
\hline 12 & 95,9 & 61,1 & 84,9 \\
\hline 24 & 74,4 & 39,6 & 57,4 \\
\hline 36 & 53,5 & 27,5 & 43,8 \\
\hline 48 & 37,6 & 16,5 & 33,2 \\
\hline 60 & 30,7 & & 28,0 \\
\hline
\end{tabular}

At present, evidence-based medicine does not provide a definitive answer as to the appropriateness of CT in stage II RC and in elderly patients.

\section{THE AIM}

The aim was to evaluate and analyze early and late results of treatment of patients with rectal cancer after chemotherapy.

\section{MATERIALS AND METHODS}

The study is based on the results of observation of 779 rectal cancer (RC) patients who were treated in the municipal institution "Precarpathian Clinical Oncology Centre" for the period during 2012-2018.

The early and late results of chemotherapy treatment of rectal cancer were studied and evaluated.

All patients were divided according to the stage of the disease (TNM system), and patients with stage II, III, and IV rectal cancer were included into the study. We analyzed the obtained results by comparing the studied indicators within each of the stages of colon cancer and together for the total number of patients, determining their impact on survival.

\section{RESULTS}

\section{ANALYSIS OF THE OVERALL SURVIVAL OF PATIENTS WITH STAGE II RC ACCORDING TO THE PCT REGIMEN}

Patients with stage II RC accounted for $67.8 \%$ of the total number of patients (528 people). $97.2 \%$ of them underwent special treatment (513 patients). 67 patients $(12.7 \%)$ underwent surgical treatment. Surgery + chemotherapy was prescribed to 32 people, which is $6.1 \% .15$ patients $(2.8 \%)$ received chemotherapy as an independent method of treatment. 144 patients received radiation therapy as an independent method, which is $27.3 \%$. Another 34 patients had the following treatment: surgery + chemotherapy + radiation therapy (6.4\%). 213 patients $(40.3 \%)$ received surgical + radiation treatment. Chemotherapy + radiation treatment was prescribed for $1.5 \%$ of patients ( 8 people). 


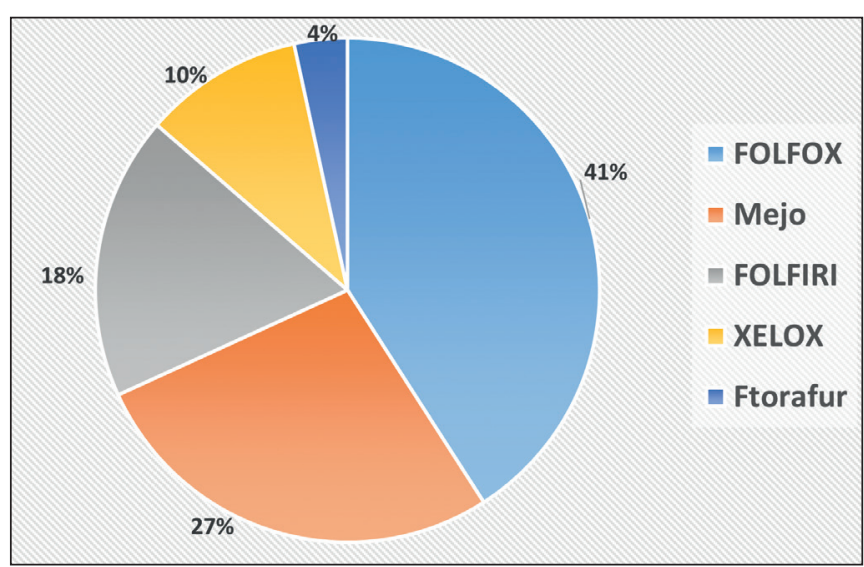

Fig. 1. Structure of chemotherapeutic treatment of stage II RC

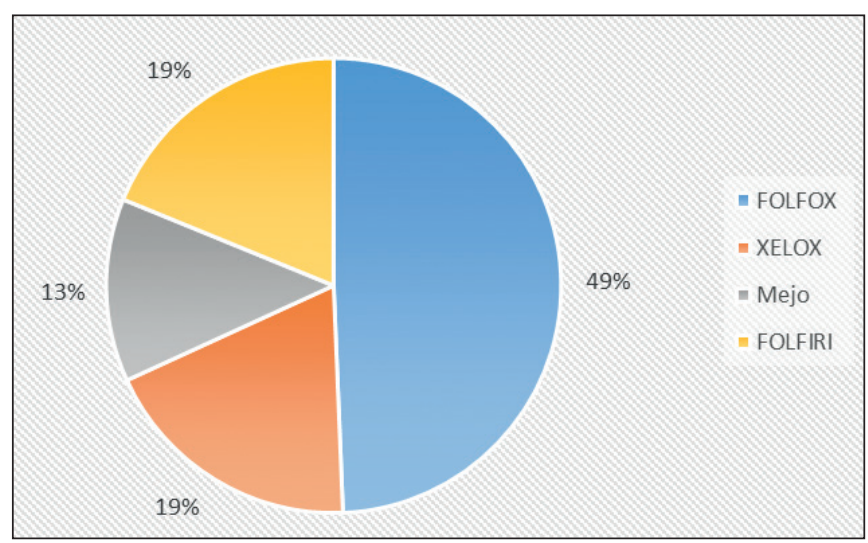

Fig. 3. Structure of chemotherapeutic treatment of stage III RC

Of all these groups, 88 patients with unfavourable prognostic factors, according to NCCN, received totally chemotherapy.

In the structure of chemotherapeutic treatment of stage II $\mathrm{RC}$, most patients followed FOLFOX treatment regimen 36 patients (40.9\%). Mejo was received by 24 people, which is $27.3 \%$. 16 patients (18.2\%) underwent FOLFIRI treatment regimen. Another 9 patients followed the XELOX chemotherapy regimen (10.2\%). In three cases, patients received Tegafur monotherapy (3.4\%) (Fig. 1).

For comparative analysis of the effectiveness of the RC chemotherapy regimen in patients with stage II, the first group of patients received FOLFIRI treatment regimen, the second group followed FOLFOX, the third group consisted of patients who received chemotherapy according to Mejo regimen, and the fourth group followed XELOX treatment regimen. Indicators of overall cumulative survival in patients of these groups are shown in Fig. 2 (Cumulative survival of RC patients according to the chemotherapy treatment regimen).

In Table I a detailed comparative analysis of the percentage of patients who survived treatment with FOLFIRI, FOLFOX, Mejo and XELOX PCT regimens is presented; these regimens are compared at identical intervals.

A comparative analysis of patient survival rates was started at the sixth month of follow-up, with the highest percentage of surviving patients recorded in the FOLFOX group (98.4\%); slightly worse results were in the group of

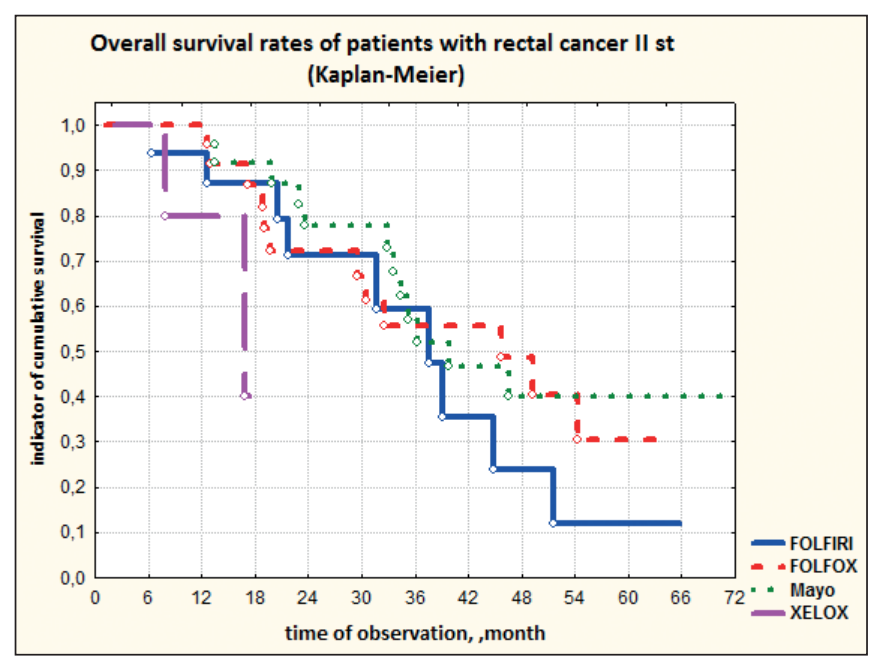

Fig. 2. Cumulative survival of patients with stage II $R C$ according to the chemotherapeutic treatment regimen

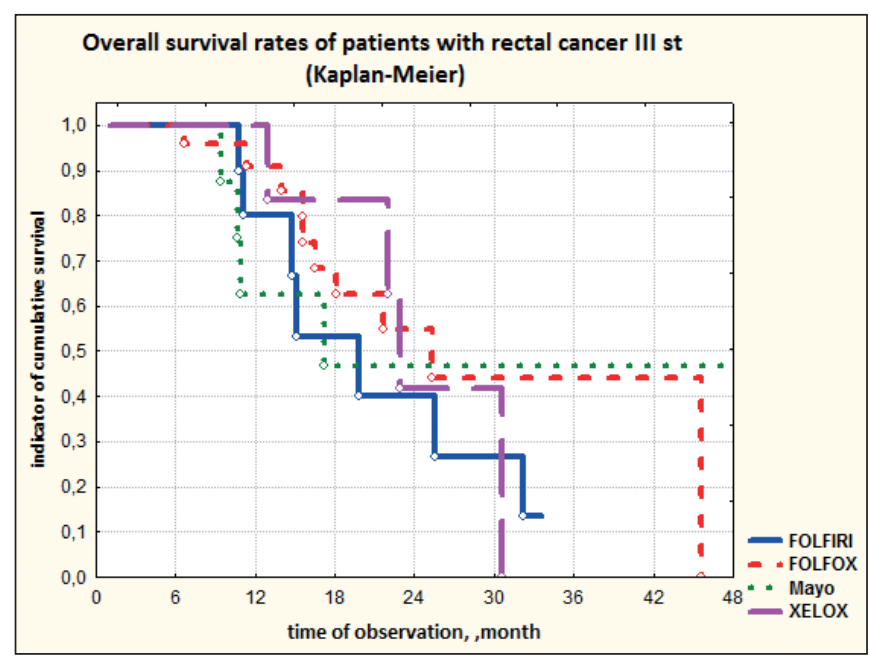

Fig. 4. Cumulative survival of patients with stage III RC according to the chemotherapeutic treatment regimen

patients receiving Mejo chemotherapy regimen $-97.9 \%$ of survivors. The lowest patient survival rate was recorded in the XELOX group, namely $-89.3 \%$.

At the $12^{\text {th }}$ month of follow-up, this trend continued: in the groups of patients who followed FOLFOX and Mejo regimens, the same survival rates were observed: $96.3 \%$ and $95.9 \%$, respectively. The worst indicators were in the XELOX group - $65.1 \%$.

A two-year follow-up showed that the highest percentage of surviving patients was registered in the Mejo group - $74.4 \%$, slightly worse results were in the groups of patients receiving FOLFOX and FOLFIRI chemotherapy $-68.5 \%$ and $68.4 \%$, respectively. There were no patients receiving XELOX treatment.

At the $36^{\text {th }}$ month of follow-up, the percentage of surviving patients in the FOLFOX, FOLFIRI and Mejo treatment groups was virtually the same: $52.7 \%, 54.3 \%$ and $53.5 \%$, respectively.

At the $48^{\text {th }}$ month of follow-up, the highest percentage of surviving patients was recorded in the FOLFOX group (43.1\%), the worst results were in patients who underwent PCT according to the FOLFIRI regimen (21.7\%). 


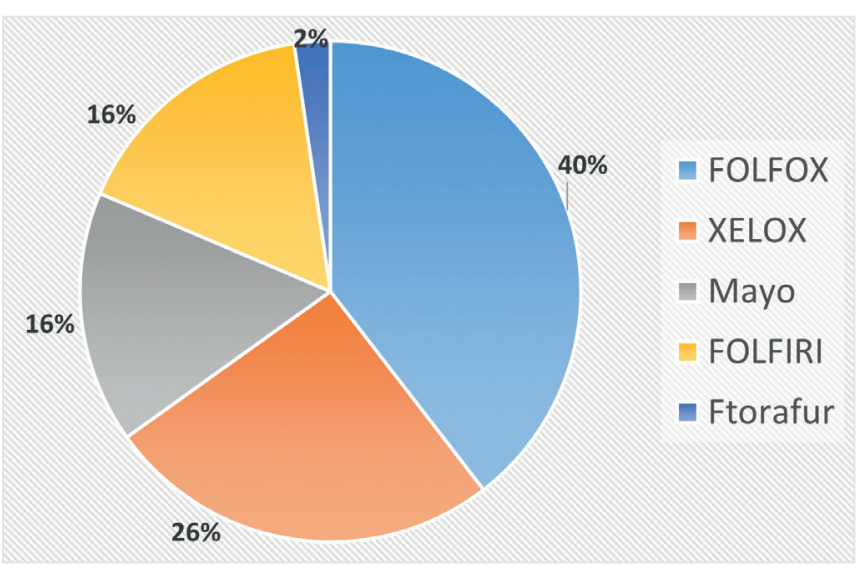

Fig. 5. Structure of chemotherapeutic treatment of stage IV RC

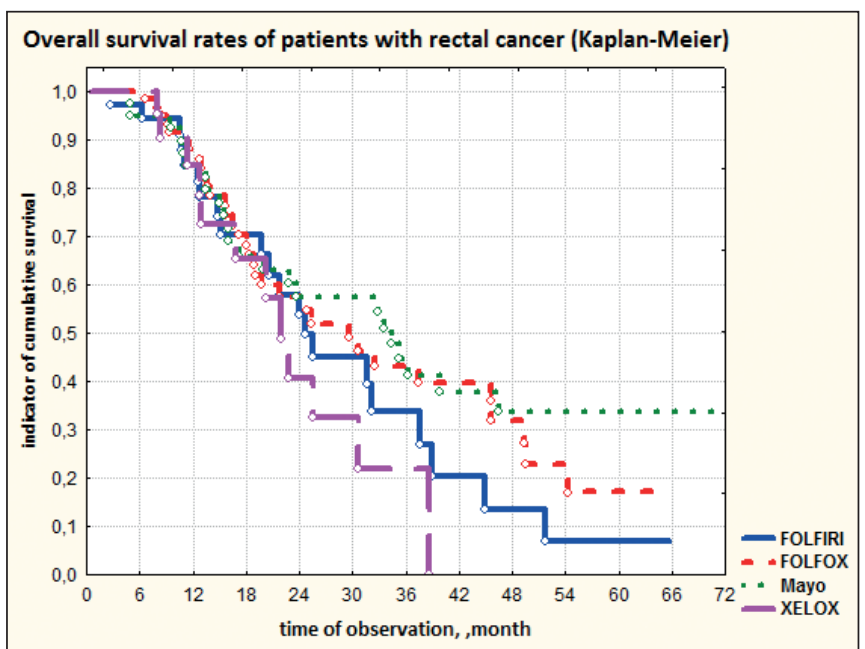

Fig. 7. Cumulative survival of patients with RC according to the chemotherapy treatment regimen

The last comparative analysis was performed at the $60^{\text {th }}$ month of follow-up: the highest percentage of surviving patients was registered in the Mejo group (30.7\%), slightly worse - in the FOLFOX group (23.5\%), the worst - in patients with PCT according to FOLFIRI regimen (5.4\%).

\section{ANALYSIS OF THE OVERALL SURVIVAL OF PATIENTS WITH STAGE III RC ACCORDING TO THE PCT REGIMEN}

Patients with stage III RC accounted for $18.7 \%$ of the total number of patients (146 people). Of these, $97.9 \%$ underwent special treatment (143 patients). 17 patients (11.6\%) received surgical treatment. 19 people $(13 \%)$ had surgery + chemotherapy. 3 patients (2\%) received chemotherapy as an independent method of treatment. Radiation therapy, as an independent method, was followed by 9 patients (6.2\%). Another 38 patients underwent surgery + chemotherapy + radiation therapy (26\%). 48 patients $(32.9 \%)$ received surgical + radiation treatment. Chemotherapy + radiation treatment was prescribed to $6.2 \%$ of patients ( 9 people).

Of all these groups, 69 patients totally received chemotherapy.

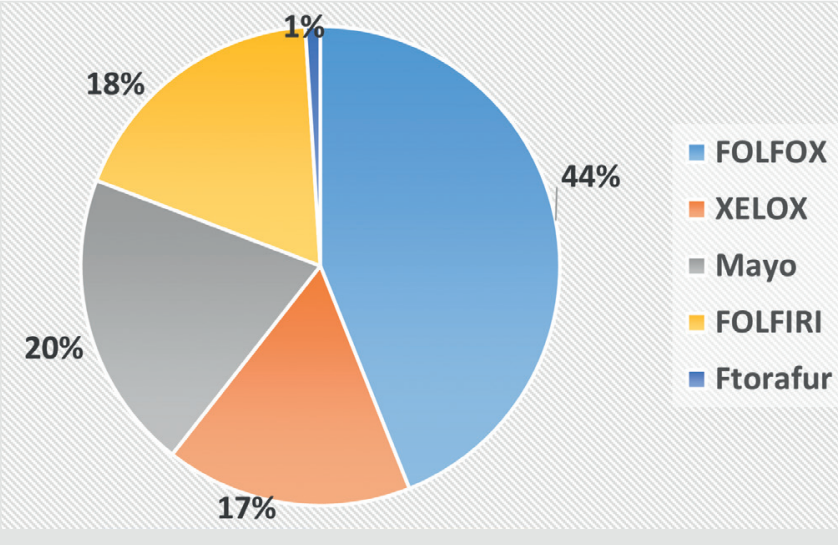

Fig. 6. Structure of chemotherapeutic treatment of stage I-IV RC

In the structure of chemotherapy treatment of patients with stage III RC, the majority of patients received FOLFOX treatment - 34 persons (49.3\%) out of 69 patients who underwent chemotherapeutic treatment. 13 patients (18.8\%) received chemotherapy treatment according to FOLFIRI and XELOX regimens. Another 9 patients had monochemotherapy according to the Mejo regimen (13\%) (Fig. 3).

For the comparative analysis of the effectiveness of the chemotherapeutic treatment regimen of RC in patients with stage III, the first group of patients received FOLFIRI regimen, the second group consisted of the patients who followed FOLFOX regimen, the third group received XELOX, and the fourth group followed Mejo regimen.

Indicators of overall cumulative survival in patients of these groups are shown in Fig. 4 (Cumulative survival of patients with stage III RC according to the chemotherapeutic treatment regimen).

In Table II a detailed comparative analysis of the percentage of patients who survived treatment with FOLFIRI, FOLFOX, XELOX and Mejo PCT regimens is presented; these regimens are compared at identical intervals.

A comparative analysis of patient survival rates was started at the sixth month of follow-up, with the highest percentage of surviving patients recorded in the FOLFOX group (98.3\%); slightly worse results were in the group of patients receiving FOLFIRI chemotherapy regimen $96.0 \%$ of survivors. The lowest patient survival rate was registered in the Mejo group, namely $94.4 \%$.

Subsequent one-year follow-up showed the following data: the highest survival rates were in patients in the XELOX and FOLFOX groups, and the worst ones were in the FOLFIRI group.

At the $24^{\text {th }}$ and $36^{\text {th }}$ month of follow-up, the highest percentage of surviving patients was observed in the FOLFOX group: $54.2 \%$ and $32.5 \%$, respectively. From the $36^{\text {th }}$ month, only those patients who received treatment according to the FOLFOX and Mejo regimens remained under observation.

In fact, at all time intervals, the highest percentage of surviving patients was registered in the FOLFOX group, but at the $36^{\text {th }}$ month of follow-up, there were only 2 persons who followed the Mejo treatment (16.5\% of surviving patients). 
ANALYSIS OF THE OVERALL SURVIVAL OF PATIENTS WITH STAGE IV RC ACCORDING TO THE CHEMOTHERAPY TREATMENT

Of the 779 rectal cancer (RC) patients who had been treated at the municipal institution "Carpathian Clinical Oncology Centre" for the period during 2012-2018, 105 patients (13.5\%) had stage IV RC. 88 of them (83.8\%) underwent special treatment. 31 patients $(29.5 \%)$ received surgical treatment. 19 people (18.1\%) followed surgery + chemotherapy. 13 people $(12.4 \%)$ received chemotherapy as an independent method of treatment. Radiation therapy, as an independent method, was received by 11 patients $(10.5 \%)$. Another 8 patients underwent surgery + chemotherapy + radiation therapy $(7.6 \%) .3$ patients $(2.9 \%)$ received surgi$\mathrm{cal}+$ radiation therapy, and the same number of patients (2.9\%) had chemotherapeutic + radiation treatment.

Of all these groups, 43 patients totally received chemotherapy.

FOLFOX and XELOX regimens were dominant in the structure of chemotherapeutic treatment - 39.5\% (17 patients) and $25.6 \%$ (11 patients), respectively.

Mejo and FOLFIRI regimens were followed by the same number of patients: $16.3 \%$ (7 patients); in one case patients received Tegafur monotherapy (2.3\%) (Fig. 5).

A comparative analysis of the effectiveness of chemotherapeutic treatment regimens in patients with stage IV $\mathrm{RC}$ was not performed because of the insufficient number of patients with chemotherapeutic treatment for adequate statistical analysis.

\section{ANALYSIS OF THE OVERALL SURVIVAL OF PATIENTS WITH RC ACCORDING TO THE PCT REGIMEN, REGARDLESS OF THE STAGE OF THE DISEASE}

773 RC patients took part in the follow-up; of these, 744 patients (96.2\%) underwent special treatment. 115 patients (15.5\%) received surgical treatment. 70 people $(9.4 \%)$ had surgery + chemotherapy. 31 patients $(4.2 \%)$ received chemotherapy as an independent method of treatment. Radiation therapy, as an independent method, was prescribed to 164 patients (22\%). Another 80 patients (10.8\%) underwent surgery + chemotherapy + radiation therapy. 264 patients $(35.5 \%)$ received surgical + radiation treatment. Chemotherapy + radiation treatment were prescribed to $2.7 \%$ of patients (20 people).

200 patients from all these groups totally underwent chemotherapy.

87 RC patients (43.5\%) followed FOLFOX regimen in the structure of chemotherapeutic treatment. 40 people $(20 \%)$ received Mejo regimen. FOLFIRI was prescribed to $36 \mathrm{pa}-$ tients, which is $18 \%$. Another 33 patients (16.5\%) received chemotherapy with the XELOX regimen. In four cases, patients underwent Tegafur monotherapy (2\%) (Fig. 6).

For comparative analysis of the effectiveness of the chemotherapy treatment regimen in RC patients, four study groups were formed: the FOLFIRI, FOLFOX, XELOX and Mejo. Indicators of overall cumulative survival analysis of patients of these groups are shown in Fig. 7 (Cumulative survival of patients with $\mathrm{RC}$ according to the chemotherapy treatment regimen).

In Table III a detailed comparative analysis of the percentage of patients who survived treatment with FOLFIRI, FOLFOX, XELOX and Mejo PCT regimens is presented; these regimens are compared at identical intervals.

A comparative analysis of patient survival rates was started at the sixth month of follow-up, with the highest percentage of surviving patients recorded in the FOLFOX group (99.3\%); slightly worse results were in the group of patients receiving FOLFIRI chemotherapy regimen 97.2\% of survivors. The lowest patient survival rate was registered in the Mejo group, namely $95.0 \%$.

At the $24^{\text {th }}$ and $36^{\text {th }}$ month of follow-up, the highest percentage of surviving patients was observed in the FOLFOX group: $54.2 \%$ and $32.5 \%$, respectively. From the $36^{\text {th }}$ month, only those patients who received treatment according to the FOLFOX and Mejo regimens remained under observation.

At the $12^{\text {th }}$ month of follow-up, the following data were obtained: the highest percentage of surviving patients was recorded in the FOLFOX group (87.7\%); slightly worse results were in the groups of patients receiving FOLFIRI and Mejo chemotherapy regimens - $85 \%$ and $84.9 \%$ of survivors, respectively. The lowest patient survival rate $(79.2 \%)$ was recorded in the XELOX group.

At a subsequent two-year follow-up, almost identical survival rates were recorded in the FOLFIRI, FOLFOX and Mejo groups - 58.1\%, 56.7\% and 57.4\%, respectively; and significantly worse results were in the group of patients receiving chemotherapy treatment according to the XELOX regimen $-39.3 \%$ of survivors.

At the $36^{\text {th }}$ month of follow-up, the percentage of surviving patients in the FOLFOX and Mejo treatment groups was virtually the same: $42.5 \%, 43.8 \%$, respectively; slightly worse results were in the FOLFIRI group (33.5\%). Significantly worse results were in the group of patients receiving chemotherapy with the XELOX regimen $-9.2 \%$ of survivors.

At the $48^{\text {th }}$ month of follow-up, the highest percentage of surviving patients was recorded in the Mejo group (33.2\%); slightly worse results were in RC patients following the FOLFOX regimen $(30.8 \%)$, the worst results were in $\mathrm{RC}$ patients who were treated according to the FOLFIRI regimen (13.4\%). There were no follow-up patients receiving XELOX treatment.

The last comparative analysis was performed at the $60^{\text {th }}$ month of follow-up: the highest percentage of surviving patients was recorded in the Mejo group (28.0\%), slightly worse results were in the FOLFOX group (14.2\%), and the worst data were in RC patients following the FOLFIRI regimen $(3.4 \%)$.

\section{ANALYSIS OF PATIENTS' AGE AND PCT REGIMEN}

Aging is a progressive multi-organ reduction of the body's functional reserves with a corresponding decrease in tolerance to stress, including chemotherapy (CT). There is a 
decrease in the reserves of red bone marrow and metabolic properties of the liver. So, these circumstances increase the risk of side effects of CT in the elderly.

Age-related decline in bone marrow reserves causes the development of unpredictable myelotoxicity and an increase in the incidence of deep neutropenia on the background of standard chemotherapeutic regimens (5-FU + leucovorin \pm irinotecan, FOLFOX). The XELOX regimen does not show an increase in toxicity to the elderly. The analysis of patients' age and the prescribed regimen of chemotherapeutic treatment was carried out (Table IV).

\section{DISCUSSION}

To better understand the results of chemotherapeutic treatment of patients, the analysis of the effectiveness of the FOLFOX regimen at different stages of RC (Table V), FOLFIRI regimen at different stages of RC (Table VI), XELOX regimen at different stages of RC (Table VII), Mejo regimen at different stages of RC (Table VIII), and also the analysis of patients' age structure in correlation with the received chemotherapeutic treatment was carried out.

When analyzing the age of patients and the PCT regimen, the identity for stages II and IV RC was noticed; Tegafur monotherapy was prescribed to older patients, as the choice of CT regimen was based on the following principles: the patient's ability to tolerate chemotherapy, the benefit-harm ratio of anticancer therapy in the particular case (taking into account concomitant pathology), the impact of cancer on the duration and quality of life of the patient.

Further analysis was performed on correlations between the following study parameters: colon cancer stage, treatment received (surgery, chemotherapy), status (registered, deceased), sex of patients, localization of the primary tumour. The observed correlations are significant at $\mathrm{p}<$ 0.05000 .

The most significant correlative dependence was between:

- stage and treatment (744 observations, $\mathrm{p}=0.000000)$;

- localization of the primary tumour and chemotherapy treatment (200 observations, $p=0,021463)$;

- sex and treatment, (744 observations, $\mathrm{p}=0.007464$ );

No relationship was found between:

- sex and chemotherapy treatment, (200 observations, $\mathrm{p}=0.582047$ );

- stage and chemotherapy treatment (200 observations, $\mathrm{p}=0,224006$ );

- status and chemotherapy treatment (200 observations, $\mathrm{p}=0.347195)$.

\section{CONCLUSIONS}

According to the results, the overall survival of patients correlates with the stage of RC and chemotherapy treatment regimen.

In patients with stage II colon cancer the most effective PCT regimen was Mejo - $30.7 \%$ of patients who survived at 5 years of follow-up.
For patients with stage III RC, at all time intervals, the highest percentage of surviving was in those who followed the FOLFOX chemotherapy, but at the $36^{\text {th }}$ month only 2 people who received Mejo treatment stayed alive (16.5\% of surviving patients).

Analyzing the data obtained in RC patients, without gradation at the stage it can be stated that at the $60^{\text {th }}$ month of follow-up the highest percentage of surviving patients was recorded in the Mejo group (28.0\%), slightly worse results were in the FOLFOX group $(14,2 \%)$, the worst results were in RC patients according to the FOLFIRI regimen (3.4\%).

\section{REFERENCES}

1. Bondar G.V., Dumansky Yu.V., Popovych 0.Yu. et al. Onkolohiia [Oncology]. Kyiv: Medytsyna; 2013, 312p. (In Ukrainian).

2. Jamal A., Cancer C.A., Clin J. et al. Global cancer statistics. 2013;63:11-30.

3. Fedorenko Z.P., Mykhailovych Yu.Y., Gulak L.O. et al. Rak v Ukraini 20172018 [Cancer in Ukraine 2017-2018]. Biul.Nats.Kantser-reiestruUkrainy. 2019; 17:144. (In Ukrainian).

4. Hotko Ye.S. Suchasni aspeky khimioterapii raku tovstoii kyshky [Modern aspects of chemotherapy of rectal cancer]. Zdoroviya Ukraiiny. 2009; 1(5):3-4. (In Ukrainian).

5. Tyuliandin C.A., Moiseyenko V.M. Prakticheskaia Onkolohia: izbrannyelektsii [Practical Oncology: selected lectures]. TOMM tsentr. 2004. (In Ukrainian).

6. Cynamon J., Atar E., Steiner A. et al. Catheterinduced vasospasm in the treatment of acute lower gastrointestinal bleeding. J. Vasc. Interv. Radiol, 2003; 14(2):211-216.

7. Du D., SuZ.,Wang D. et al. Optimal interval to surgery after neoadjuvant chemoradiotherapy in rectal cancer: a systematic review and metaanalysis. Clin Colorectal Cancer. 2017; (15):1533-0028(17)30183-4.

8. Peng J., Lin J., Zeng Z. et al. Addition of oxaliplatin to capecitabine-based preoperative chemoradiotherapy for locally advanced rectal cancer: long-term outcome of a phase ll study. Oncol Lett. 2017; 14(4):4543-50. doi:10.3892/ol.2017.6764.

9. Singh K., Gupta M.K., Seam R.K. et al. A prospective randomized trial comparing capecitabine-based chemoradiotherapy with 5-FUbased chemoradiotherapy in neoadjuvant setting in locally advanced carcinoma rectum. Indian J Cancer. 2017; 54(1):347-51. doi: 10.4103/ ijc.IJC_174_17.

10. Fernández-Martos C., Nogué M., Cejas P. et al. The role of capecitabine in locally advanced rectal cancer treatment: an update. Drugs. 2012; 72(8):1057-73. doi: 10.2165/11633870-000000000-00000.

11. Kornek G., Scheithauer W., Anghel R. et al. Konsensus shchodo medykamentoznoho likuvannia raku [Consencus of medication-based treatment of rectal cancer]. Medytsyna svitu. 2008; 1(6):79-90. (InUkrainian).

12. Meyerhardt J.A., Mayer R.J. et al. Systemne likuvanniya kolorektalnoho raku [Systemic treatment of colorectal cancer]. Medytsyna svitu, 2008; 5(1):476-486 (In Ukrainian).

13. Cividalli A., Ceciarelli F., Livdi E. et al. Radiosensitization by oxaliplatin in a mouse adenocarcinoma: influence of treatment schedule. Int J Radiat Oncol Biol Phys. 2002; 52:1092-8.

14. Jean G.W., Shah S.R. Epidermal growth factor receptor monoclonal antibodies for the treatment of metastatic colorectal cancer. Phatmacotherapy, 2008; 28(6):742-782.

15. Rahbari N., Weitz J., Hohenberger W. et al. Definition and grading of anastomotic leakage following anterior resection of the rectum: a proposal by the International Study Group of Rectal Cancer. Surgery, 2010; 147(3):339-51. 
ORCID and contributionship:

Bohdan Tataryn: 0000-0002-4957-0691 B,D

Anna Kryzhanivska: 0000-0003-4415-4696 E,F

Volodymyr Holotiuk: 0000-0003-4798-6893 ${ }^{\mathrm{C}}$

Alina Andriiv: 0000-0002-4905-5497 A

Olha Ivantsiv: 0000-0002-4366-6406 ${ }^{A}$

\section{Conflict of interest:}

The Authors declare no conflict of interest.

\section{CORRESPONDING AUTHOR}

\section{Bohdan Tataryn}

Ivano-Frankivsk National Medical University

17 Medychna st., 76018 Ivano-Frankivsk, Ukraine

tel: +380501669043

e-mail:boda.tataryn@gmail.com

Received: 17.07 .2020

Accepted: 02.06.2021

A - Work concept and design, B - Data collection and analysis, C - Responsibility for statistical analysis,

$\mathbf{D}$-Writing the article, $\mathbf{E}$-Critical review, $\mathbf{F}$-Final approval of the article 